\title{
APPLICATION OF MULTI-CRITERIA DECISION MAKING FOR THE SELECTION OF SENSING TOOLS FOR HISTORICAL GRAVESTONES
}

\author{
Miroslavas Pavlovskis ${ }^{1}$, Maria Chizhova ${ }^{2}$, John Hindmarch $^{2}$, Mona Hess $^{2}$ \\ ${ }^{1}$ Department of Construction Technology and Management, Faculty of Civil Engineering, Vilnius Gediminas Technical \\ University, Vilnius, Lithuania - miroslavas.pavlovskis@vgtu.lt \\ ${ }^{2}$ University of Bamberg, Institute of Archaeology, Heritage Sciences and Art History, Germany - maria.chizhova@uni- \\ bamberg.de,john.hindmarch@uni-bamberg.de,mona.hess@uni-bamberg.de
}

KEY WORDS: photogrammetry, 3D, scanning, Jewish, cemetery, gravestones, inscription, multi-criteria decision making

\begin{abstract}
:
This paper describes a feasibility study for the digitisation of gravestones, specifically Jewish gravestones, alongside an implementation of Multi-Criteria Decision Making. MCDM methods are common in other contexts, and have been used to address issues particular to design, organisation and management of large-scale construction and engineering projects. They are, however, novel in the context of cultural heritage. This paper will examine the potentials of non-contact sensor technologies (including photogrammetry via Structure from Motion, structured light scanning and terrestrial laser scanning) to record, model and archive the stones and their inscriptions. The various methodologies will be assessed against set criteria, specifically speed, resolution, readability and scalability for mass recording, from MCDM including criteria given by humanities scholars in the field of history, theology and Jewish studies.
\end{abstract}

\section{INTRODUCTION}

\subsection{Motivation}

The cemetery in Hebrew is called the "House of Eternity" and the "House of Life", where the dead are to have eternal rest. (IAJGS, 2020)

There are around 10,000 known Jewish cemetery sites across the 46 member states of the Council of Europe. Before World War II more than seven million Jews lived in Central and Eastern Europe, therefore burial sites and cemeteries are a direct physical evidence of this presence. The inscribed Jewish gravestones are artefacts preserving memories of individuals and families. They are invaluable repositories of historic information and collective memory, and as such the inventorying of the ephemeral heritage they contain is desirable for the descendants of Jewish families in both Germany and worldwide, as well as for historians and theological researchers.

Eighty years later, many cemeteries are lost or endangered, but are still present in urban or rural areas, and often cared for by volunteer organisations. Multiple worldwide initiatives aim to document and preserve Jewish graveyards and to transcribe their gravestones. The motivation to document Jewish burial sites and interments, is driven by the worldwide interest in Jewish ancestry and heritage as well as individual's searches for burial places of ancestors and relatives. Current initiatives include Jewish Heritage Europe, JewishGen, European Jewish Cemeteries Initiative (ESJF, since 2015), Lo Tishkach Foundation European Jewish Cemeteries Initiative, Jewish Epitaphs, and others.

In Germany, the documentation of Jewish Gravestones has been approached in a systematic fashion in publications, for example in Wuerzburg (Müller, 2011), and recently also through systematic semantic databases, for example epidat - Research Platform for Jewish Epigraphy (Steinheim Institut, 2020). In Bavaria, this includes the development of databases (Klemm, 2020). Significant work has been done to systematise the photography, manual transcription and damage and condition evaluation (conservation, petrography, and typology) of these stones (Arera-Rütenik et al. 2011). A new three-year initiative to document all Bavarian Jewish graveyards was launched in December 2019.

The provision of comprehensive remote access to collections of photographs, transcriptions and searchable databases is ongoing, but still not nearly complete. The sheer number of Jewish cemeteries and gravestones makes the documentation and systematic analysis a huge task. Steps towards mass digitisation (in 3D) and automated extraction of information has hitherto not been undertaken on a large scale.

The documentation methods described in this paper are noncontact optical recording and multi-criteria decision-making. MCDM methods are common in other contexts, and have been used to address issues particular to design, organisation and management of large-scale construction and engineering projects. Multiple criteria decision-making methods are formal mathematical techniques for determining an optimal choice from a set of potential alternatives in situations where those alternatives must be evaluated according to a variety of often conflicting and contradictory criteria.

They are, however, novel in the context of cultural heritage. With thousands of gravestones just in the local area of Franconia/ North Bavaria, and hundreds of thousands of stones across Germany alone, it is vital that the various technologies are assessed carefully and accurately. An aid for an objective assessment and rationale for technical digitisation and recording of these valuable stone-archives should be given to scholars of the Jewish studies and epigraphy.

\subsection{Research object}

This project will include multiple cemeteries, but for the purposes of this paper, we will examine the Jewish cemetery in Laudenbach. This 400-year-old cemetery is located in the state of Bavaria, in the south west of Germany. The stones are engraved 
with Hebrew and German text, containing not only names and dates of birth but also places of origin, occupations and sometimes the entire life stories of the deceased. As such, the stones comprise a rich historical archive for the Jewish communities throughout the Main Spessart Circle (Alemannia Judaica 2013) (see Fig. 1).

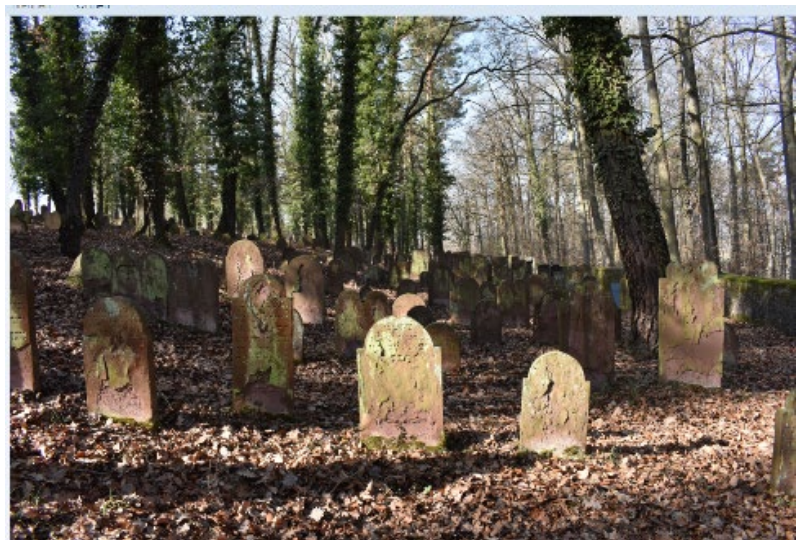

Figure 1. Jewish cemetery in Laudenbach (Germany)

Unfortunately, the 'memory archive' is at high risk and preservation of the stones themselves is difficult to impossible. The local Buntsandstein (coloured/red sandstone) is soft and readily absorbs moisture meaning the stones suffer from extreme weathering. In particular, winter frosts can cause catastrophic damage. The older gravestones are particularly vulnerable. Many of the inscriptions are already irrevocably damaged and their valuable historical information lost for good. Many of the Hebrew inscriptions are already irretrievably lost (Figure 2).
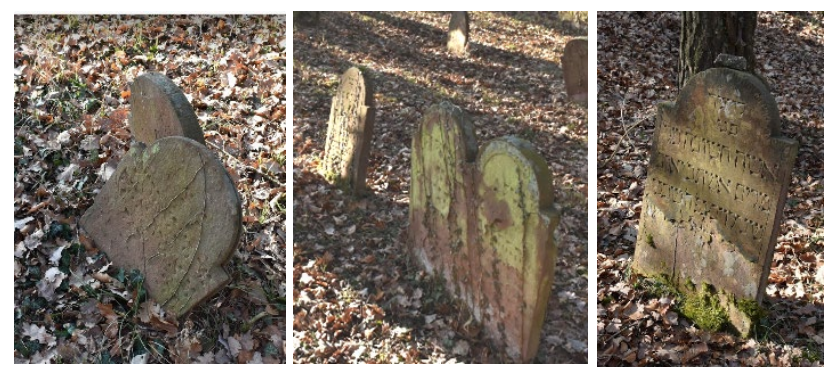

Figure 2. Samples of the damaged gravestones in Laudenbach

\section{STATE OF THE ART}

\subsection{Multi-Criteria Decision Making (MCDM)}

The analysis of different tasks necessary to digitally record the gravestones in 3D and analyse the scripts raises the question of how to make rational decisions regarding quality of the recording versus speed, at the same time as evaluating different alternatives according to possibly conflicting criteria. Here, a humanities question, the reading and analysis of inscriptions, can turn to the engineering- and statistical perspective to achieve its goals.

Multi-criteria decision-making methods (MCDM) are an approach to evaluating decisions to select the best option from a range of possible alternatives according to various, often contradictory, criteria or characteristics. The basis of MCDM methods is that their solution is not always the best according to every criteria; the result is appropriate when all criteria are taken into consideration, but not the best for every (or indeed, any) criterion individually.
There are many ways to solve multi-criteria problems. Each method differs in its algorithm and defines various aspects of the alternatives analysed. A general overview of MCDM methods and their application to technological problems is available in several research papers (Zavadskas et al., 2016; Zavadskas et al., 2018; Stojčić et al., 2019).

As the selection of sensing tools for historical gravestones is described by multiple criteria (see section 4.2), MCDM methods can be applied to find rational solutions for recording and modelling the gravestones.

Currently used criteria decision making methods differ according to purpose, solved tasks and complexity. Each method has its own advantages and disadvantages, internal logic, and highlights the different aspect of the object or the situation in question. The best known and most commonly used is the Simple Additive Weighting (SAW) method (Hwang, Yoon 1981; Ginevičius, Podvezko 2008). Our approach, however, will use Weighted Aggregated Sum Product Assessment method with grey numbers (WASPAS-G), originally presented by Zavadskas in 2015 (Zavadskas et al 2015), building on his earlier work (Zavadskas et al 2012).

In multi-criteria approaches, it is important to determine the weights of criteria. The weight of a criteria is determined by the method of expert estimates, i.e. experts evaluate the alternatives based on experience and knowledge. Each expert's opinion and approach to the assessed criteria may differ, and there may be conflicting opinions. During the ranking stage, the most important indicator is given a rank equal to one, the second, two, and so on. Expert opinions will be harmonized when the assessments of all experts are the same, and conversely, expert opinions will disagree when assessments are contradictory (Antuchevičienè and Stasiulionis 2012).

\subsection{Methods for gravestone digitisation}

The goal of digital documentation of cemeteries is to create precise topographic maps, indicating the location of specific monuments, gravestones and trees (for orientation), documenting the single gravestone and linking to it personal information about the buried person (name, dates and other inscriptions). In addition, the monuments themselves may be of a cultural value in their typology, shape and craftsmanship.

It is necessary to define which aspects of interest are most important for the digitisation tasks, and subsequently, which method and technology would be most efficient for data acquisition. Within the framework of this article, we are focused on the documentation of individual gravestones to prepare a future research project for automatic inscription extraction and interpretation.

The digital cemetery documentation is a challenging task due to the large surface areas with many obstacles like vegetation, stones and fences to be documented. This task can be complicated, if the gravestones are affected by erosion due to vegetation, weathering and partial destruction. The campaigns for digital cemetery documentation have been undertaken in many countries around the world (Rütenik et al. 2013; Jones 2008; Gabov \& Bevan, 2011; Robinson 2018).

For the documentation of written information from the gravestones, 2D images are mostly used. This has been approached by amateur photography, as well as professional or metrological photos acquired with specific sensors (e.g. thermal IR camera (Heitger 1991), or even a multispectral approach in (Mathys et al., 2019).

(Demir \& Yogeswaran, 2018) documented the individual gravestones for further geotagging using a smartphone. Here, the text has been automatically recognized using digital image 
processing methods and the Google Tesseract OCR library in a Python environment. This method is well suited for new, undamaged gravestones with significant contrast between the gravestone background and inscriptions.

When the gravestones are weathered, destroyed or covered with vegetation they are difficult to decipher. An option is to cover the stones with a special coating (contrast spray, snow), which helps to extract the inscriptions on the monument, but this might be invasive. However, it is possible to achieve readability with noninvasive digital methods, using 3D optical surface recording of the geometry. After processing the data, the engraved script can be made readable using artificial lighting. As well, 3D information can be used for the investigation of monument surfaces or its separate details (e.g. decorations, sculptural elements, etc.).

Extracting 3D geometry from one image by generating a depth map is not an easy task (Godard et al., 2017; Eigen et al., 2014). In such cases, other photogrammetric methods could be helpful:

\section{Reflectance Transformation Imaging (RTI)}

RTI has a wide application spectrum within historical archaeology (Mytum and Peterson, 2018, Hess et al., 2018; Piquette 2017). Using basic photographic equipment and special reference spheres, an object is recorded from different positions with light from a known direction. This method allows the surface digitalisation with $\mu \mathrm{m}$ accuracy (Coules et al., 2019), analysation of its microscopic details and visualisation of individual surface features and artefacts (Earl et al., 2010). RTI has been applied for gravestone digitalisation as well (Gabov \& Bevan, 2011). The obtained information is in a 2.5D format, what, however, could be enriched with 3D data from photogrammetric approach (Miles et al. 2014) or laser scanning (Díaz-Guardamino \& Wheatley, 2013). Generally, the method yields good results and is easily available due to low-cost equipment and free software. However, it takes a lot of time, which complicates the work when digitising a large number of objects.

\section{Photogrammetry - Structure from Motion}

The photogrammetric method called Structure from Motion originates from computer vision (Marr \& Poggio, 1976) and has found a wide application in cultural heritage documentation (Stylianidis \& Remondino, 2016; Vincent et al., 2017; Kersten \& Lindstaedt, 2012). For data acquisition professional and amateur photos, video cameras, drones or a combination can be used (Luhmann et al., 2019a). The objects are recorded from different positions and viewpoints with high image overlap. After orientation and alignment of images, a photorealistic 3D object model can be generated with high accuracy (Luhmann et al. 2019b). A 3D model includes a point cloud or mesh, which could be colorized or textured. This method is quite easy to use and does not require expensive equipment. Nevertheless it is quite time consuming.

\section{Structured light scanning}

This method is often used to capture complex 3D surfaces by projection of a solid speckle pattern or fringe projection on the surface (Luhmann et al., 2019b). Due to easy to use sensors with high recording speed, this method is also common in industry (Wilm, 2016), as well as in cultural heritage documentation (Kersten et al, 2018). Structured light scanning can be achieved with expensive metrology and quality inspection-grade scanners (Steinbichler Comet) and more consumer-grade scanners (Artec Eva, Spider).

It is possible to use drones ( $\mathrm{SfM}$ ) and terrestrial laser scanning for an overview and simultaneous survey of a large number of monuments, which, however, will significantly reduce the surface recording quality of each single gravestone surface and will be hampered by the presence of intervening objects (trees and shrubs, various structures).

\section{METHODS}

The methodology for gravestone digitisation is based on the selection of the most appropriate method in the context of future further automatic extraction and interpretation of inscriptions.

In this section, three common 3D recording methods are compared. These are close-range photogrammetry, structured light scanning and terrestrial laser scanning. The methods are evaluated by selected criteria and the best method is determined using MCDM techniques.

To assess the sensor technologies for optical surface recording, we will be applying a MCDM method for ranking alternatives according to multiple criteria.

\subsection{Data acquisition}

\subsubsection{Photogrammetry/ SfM with consumer camera and macro lens}

An example gravestone represents high-resolution close-range single stone documentation here from the Jewish cemetery of Zeckendorf, Franconia (see Figure 3).

A Nikon D3400 camera was used to take 114 photos with a $40 \mathrm{~mm}$ macro lens. It took about 80 minutes to take all the images from systematic viewpoints in a horizontal and vertical grid over
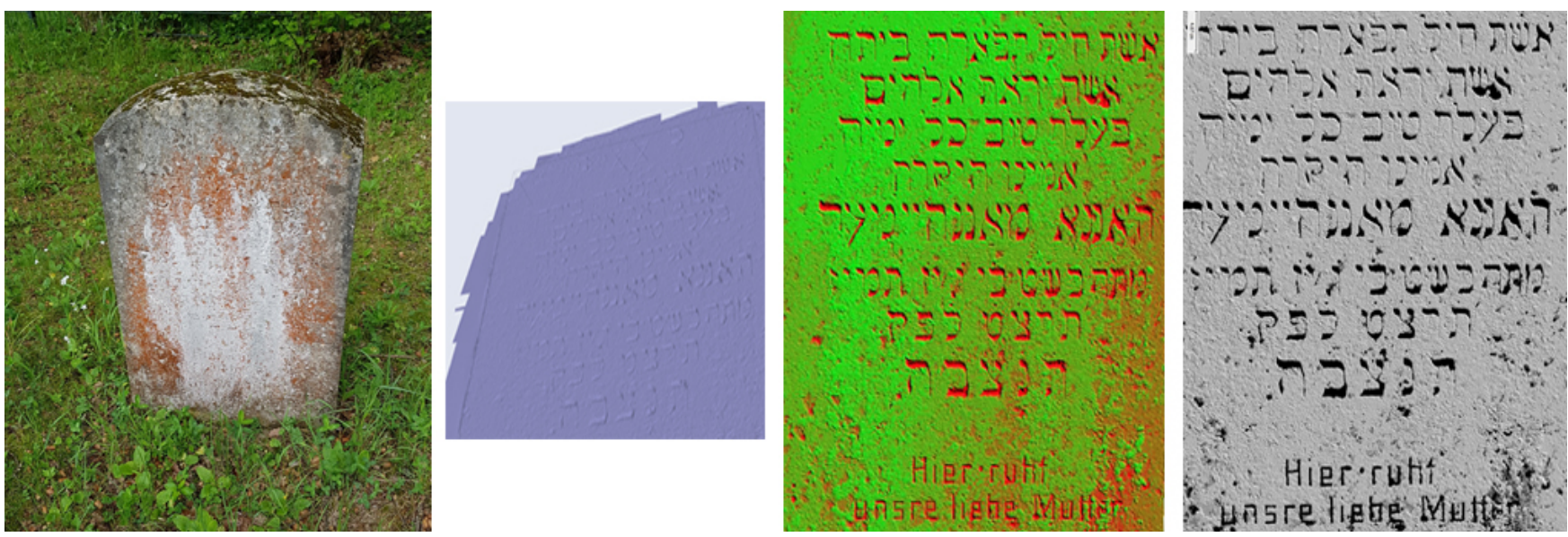

Figure 3. Photogrammetry workflow example for reading faded inscriptions. From left to right: Image of typical gravestone with highly eroded inscription; 3D model; depth map; output image with readable text. 
the surface. The ground was uneven, so the levelling of the tripod and positioning of the camera took longer than expected.

For processing a 16GB RAM laptop was used (i7-7500 CPU and a NVidia Quadro Graphics card with M520 GPU). The timing needed for the single steps of SfM in Agisoft Metashape were: 45 mins alignment, $3 \mathrm{hrs}$ dense cloud, $2.5 \mathrm{hrs}$ for Height field mesh, $1 \mathrm{hr}$ for texture. The total processing time took of 7.5 hours, including other processing steps. Most of the time used was idle, i.e. waiting for the computing to finish. With these highest computing settings, a dense point cloud of approx. $400 \mathrm{~m}$ points was achieved. Assuming an area of around $2 \mathrm{~m}^{2}=200$ points per $\mathrm{mm}^{2}$, this resulted in a resolution of between $50 \& 100$ microns.

\subsubsection{Photogrammetry/ SfM with an action camera}

Gravestones were also been captured with a low-cost GoPro camera as video. The GoPro cameras can record photos and videos. They are characterised by a very wide shooting angle $\left(170^{\circ}\right)$, which gives the recordings a certain recognition effect. All devices from Hero5 (2016) onwards have video stabilisation and voice control (GoPro 2020).

The recorded videos were processed in RealityCapture software for the photogrammetric 3D reconstruction. In Figure 4 some samples of gravestones in different materials and colours as well their 3D reconstruction (meshes) are shown. As we can see, in spite of the poor quality the letters are clear visible on the model. Furthermore, information about the stone (petroglyphic information and stone quality) and biological growth can be deducted from the colour images.

\subsubsection{Handheld Structured Light Scanning}

For the recording of gravestones with Structured Light Scanners two Artec scanners have been used - Eva and Spider. The scanners allow the creation of fast, textured and accurate $3 \mathrm{D}$ models of medium sized objects (Artec 2020).

The two scanners are hand-held and differ from each other in

- $\quad$ point accuracy $(0,05$ and $0,1 \mathrm{~mm})$,

- 3 D resolution $(0,1$ and $0,5 \mathrm{~mm})$,

- $\quad$ volume capture zone $\left(2,000 \mathrm{~cm}^{3}\right.$ and $\left.61,000 \mathrm{~cm}^{3)}\right)$,

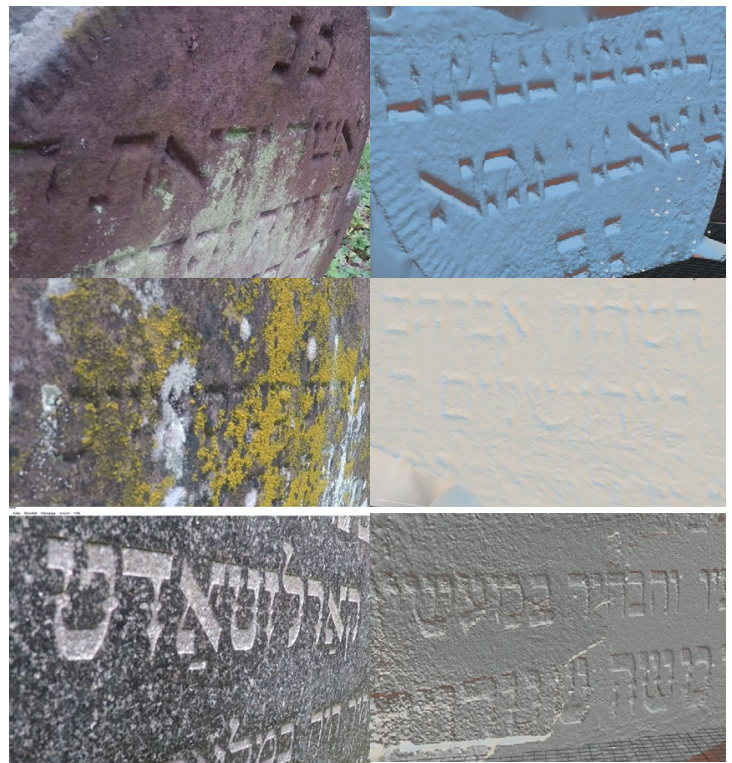

Figure 4. Examples of gravestones captured with GoPro camera (left, stills extracted from video) and processed in Reality Capture (right).
- data acquisition speed (1 million points/sec and 2 million points/sec)

- $\quad$ as well as 3D real-time recording rate (7.5 fps and 16 fps).

The accuracy evaluation and data quality from different handheld 3D scanning systems have been presented in Kersten et al, 2018 in detail.

The data was processed with Artec Studio proprietary software (see Figure 4 and Figure 5)

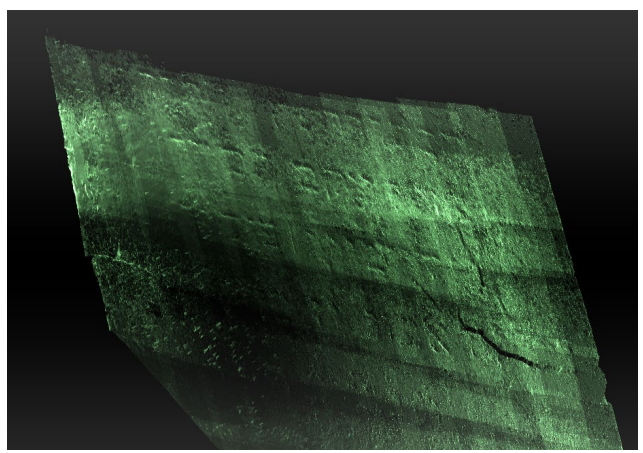

Figure 5. Pointcloud (Artec Spider) before processing.

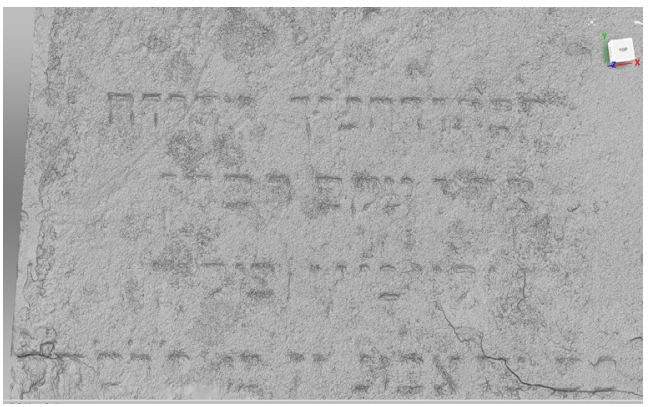

Figure 6. Surface geometry (Artec Spider) after processing.

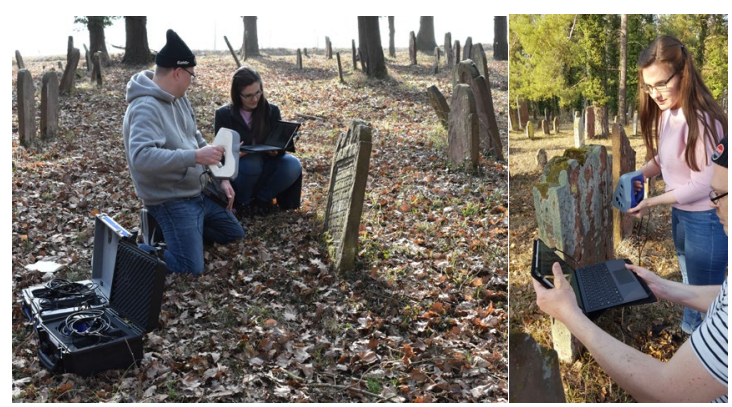

Figure 7. Handheld scanning handheld structured light scanner with Artec EVA (left) and Artec Spider (right),

\subsubsection{Terrestrial Laser scanning}

For terrestrial laser scanning the new BLK360 laser scanner by Leica Geosystems (2018) was used. The BLK360 is a compact imaging laser scanner that uses a $360^{\circ}$ laser rangefinder and $\mathrm{HD}$ panoramic images. The BLK360 creates coloured 3D point clouds accurate to the millimetre and overlaid with the $\underline{\underline{2 D}}$ images. The scans taken by the BLK360 can be registered together to complete the documentation of detailed 3D models of objects in different sizes (1-100 m). LiDAR technology allows capture of 360,000 points per second. Additionally, the scanner is equipped with a thermal imaging camera (Leica Geosystems 2020). Scan resolution depends on laser beam diameter, optics and distance to the object. 
The examples of captured gravestone at a distance of approx. $1 \mathrm{~m}$ to the scanner you can see on Figure 8 . The data has been processed in Leica Cyclone Register 360 software.
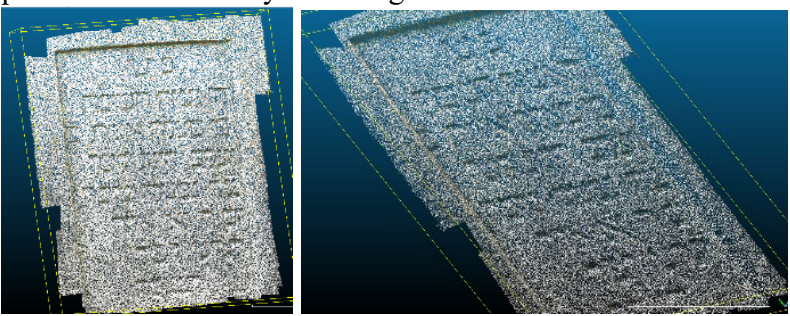

Figure 8. Examples of gravestones captured with BLK 360 laser scanner.

\subsection{WASPAS-G for multiple-criteria decision-making}

Weighted Aggregated Sum Product Assessment method with grey numbers (WASPAS-G) is a method, presented in 2015 and applied for the selection of contractors (Zavadskas et al 2015). It is an extension of an original crisp WASPAS method as described by Zavadskas et al. in 2012 (Zavadskas et al 2012). The method was also used for evaluation of assets redevelopment solutions (Pavlovskis et al 2016), for selection of most rational protective measures preventing falls from elevations (Leonavičiūtè et al. 2016), for building foundation alternatives determination (Turskis et al 2016) etc.

The WASPAS - G algorithm consists of several steps, where $\otimes x_{i j}$ to be a grey number with the lower and the upper limit. Initial decision-making matrix is then composed of grey numbers $\otimes x_{i j}=\left\lfloor x_{i j \alpha}, x_{i j \beta}\right\rfloor$, where $\mathrm{x}_{\mathrm{ij}}$ are values of alternatives assessment criteria, $i=1, \ldots, m ; j=1, \ldots, n ; m$ is number of alternatives, $\mathrm{n}$ is number of criteria according to grey system theory (Liu, Lin 2010). $\otimes \bar{x}_{i j}$ - the normalized value of the criteria; $\otimes \widehat{\mathrm{x}}_{\mathrm{ij}}$ - weighted normalized value; $\otimes \mathrm{w}_{\mathrm{ij}}$-weight of criteria; $\mathrm{P}_{\mathrm{i}^{-}}$WSM optimization criteria; $\mathrm{S}_{\mathrm{i}^{-}} \mathrm{WPM}$ optimality criteria.

WASPAS - G algorithm: (Zavadskas et al 2015)

- Creating a criteria matrix

- Criteria matrix normalizing by applying a linear method.

- Criteria with preferred maximal values are suggested to be normalized as follows:

$$
\begin{aligned}
& \otimes \bar{x}_{i j}=\frac{\otimes x_{i j}}{\max _{i} \otimes x_{i j}}, \\
& \text { i.e. } \bar{x}_{i j \alpha}=\frac{x_{i j \alpha}}{\max _{i} x_{i j \beta}} \text { and } \bar{x}_{i j \beta}=\frac{x_{i j \beta}}{\max _{i} x_{i j \beta}} .
\end{aligned}
$$

- Criteria with preferred minimal values are normalized as:

$$
\begin{aligned}
& \otimes \bar{x}_{i j}=\frac{\min _{i} \otimes x_{i j}}{\otimes x_{i j}}, \\
& \text { i.e. } \bar{x}_{i j \alpha}=\frac{\min _{i} x_{i j \alpha}}{x_{i j \beta}} \text { and } \bar{x}_{i j \beta}=\frac{\min _{i} x_{i j \alpha}}{x_{i j \alpha}} .
\end{aligned}
$$

Weighted criteria matrix creating.

$$
\begin{aligned}
& \otimes \hat{x}_{i j}=\otimes \bar{x}_{i j} w_{j} ; \\
& \hat{x}_{i j \alpha}=\bar{x}_{i j \alpha} w_{j} ; \hat{x}_{i j \beta}=\bar{x}_{i j \alpha} w_{j}
\end{aligned}
$$

WPM optimality criteria calculation

$$
\begin{aligned}
& \otimes S_{i}=\sum_{j=1}^{n} \otimes \hat{x}_{i j}, \text { or } \\
& \otimes S_{i}=0.5 \sum_{j=1}^{n}\left(\hat{x}_{i j \alpha}+\hat{x}_{i j \beta}\right) .
\end{aligned}
$$

WSM optimization criteria calculation

$$
\begin{aligned}
& \otimes P_{i}=\prod_{j=1}^{n} \otimes \bar{x}^{\otimes w_{j}}, \text { or } \\
& \otimes P_{i}=\prod_{j=1}^{n} 0.5\left(\otimes \bar{x}_{j \alpha}^{\otimes w_{j}}+\otimes \bar{x}_{j \beta}^{\otimes w_{j}}\right) .
\end{aligned}
$$

To increase calculation accuracy the aggregation coefficient $\lambda=0, \ldots, 1$ determinated:

$$
\lambda=0.5 \frac{\sum_{i=1}^{m} P_{i}}{\sum_{i=1}^{m} S_{i}} .
$$

Calculation the weighted aggregation of grey optimality functions

$$
\begin{aligned}
& \otimes Q_{i}=\lambda \otimes S_{i}+(1-\lambda) \otimes P_{i}= \\
& =\lambda \sum_{j=1}^{n} \otimes \hat{x}_{i j}+(1-\lambda) \prod_{j=1}^{n} \otimes \bar{x}^{\otimes w_{j}} .
\end{aligned}
$$

An alternative priority line (Alternative Ranking) creating.

Priority line of alternatives is determined according to the $Q_{i}$, after transforming the grey values of $\otimes Q_{i}$ to crisp values by the centre-of-area method.

\section{RESULTS}

\subsection{Data acquisition results}

The data acquisition results in terms of $3 \mathrm{D}$ recording quality from optical 3D imaging were mostly as expected. The highest resolution and including colour-calibrated colour and geometry resulted from SfM with a macro- lens. Next, in terms of resolution and accuracy was the handheld structured-light scanning, which delivered surface geometry, colour and TIN (mesh). Third ranked was the SfM from action cam video (geometry and colour), followed last by terrestrial laser scanning (geometry and colour).

\subsection{Criteria System and experts review (heritage professionals and surveying experts)}

The selection of the most preferable sensing tools for historical gravestones is analysed regarding to a set of criteria. Since this project is limited in time and resources, we certainly need to consider the price of the used tools and the technological criteria. Also important are the quality criteria that describe the result obtained.

Considered criteria include: 


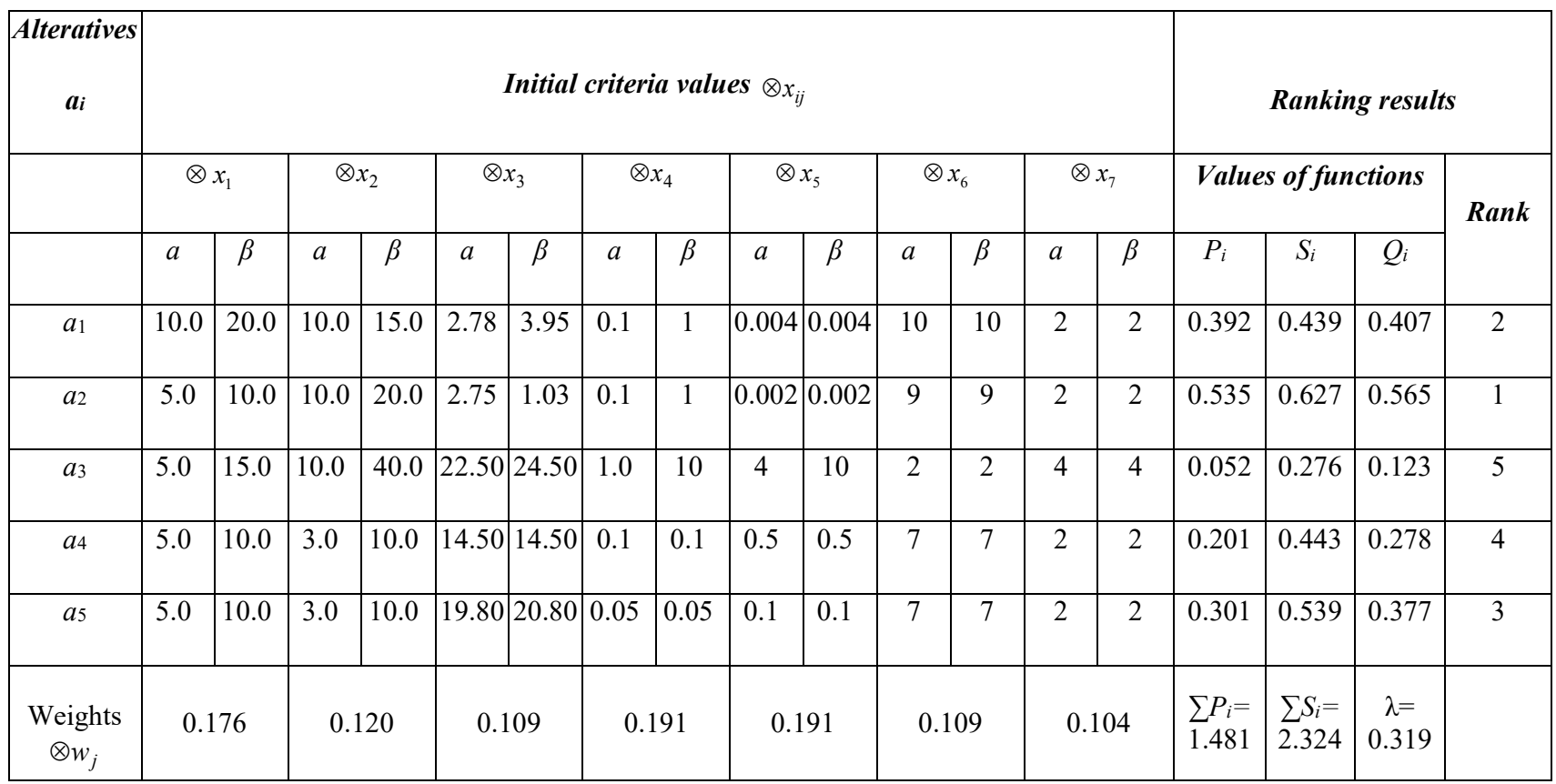

Table 1. Initial decision-making matrix and rankings in terms of criteria

Technological - economic criteria group:

$\mathrm{x}_{1}$ - Acquisition time/ Data Collection Time (Min).

$\mathrm{x}_{2}$ - Modelling time/ Processing Time (Min).

$\mathrm{x}_{3}$ - Price of equipment and software (thousands EUR).

Quality criteria group:

$\mathrm{x}_{4}-3 \mathrm{D}$ point accuracy relative to the real object in the context of target-performance comparison (mm).

$\mathrm{x}_{5}$ - Resolution as pixel pitch size or GSD (mm).

X6 - Score of photorealistic 3D modelling, which could be important for the further material investigations (credits between 1 (very low) and 10 (very high)).

$\mathrm{x}_{7}$ - Variability of raw data, which could be applied separately or combined for better gravestone investigation and especially automatic text recognition (number of raw data types: colour, 3D coordinates, intensity image, IR etc.)

For criteria $x_{1}-x_{5}$, lower values are better, and they are minimised in the optimisation process. For the $x_{6}-x_{7}$ criteria higher values are better, and they are maximised. Weights for the criteria were obtained using an expert survey. Since the study was carried out as part of a project by the 'Centre for Heritage Conservation Studies and Technologies (KDWT)' at the University of Bamberg's heritage sciences department, the experts interviewed included KDWT employees involved in recording and preserving stones at the Jewish cemetery in Laudenbach, as well as other heritage specialists.

\subsection{Calculations}

This MCDM-procedure examines the potentials of non-contact sensor technologies to record, model and preserve the stones. In the paper five alternatives are evaluated, including highresolution close-range photogrammetry by SfM with a Nikon D3400 and 40mm macro-lens ( $\left.\mathrm{a}_{1}\right)$, photogrammetry by SfM with a GoPro action camera (Video)( $\left.\mathrm{a}_{2}\right)$, terrestrial laser scanning with the BLK Leica Geosystems (a3), handheld structured-light scanning with Artec Eva (a4), handheld structured-light scanning with Artec Spider (a)).
The initial decision-making matrix describes selection of sensing tools, as well as ranking results in terms of criteria, applying WASPAS-G method (Eq. 1-7) are presented in Table 1.

\section{CONCLUSIONS}

The case study results applying WASPAS-G decision-making method confirmed that the MCDM methods are proved highly suitable to support selection of the effective sensor for optical 3D imaging of gravestones.

MCDM-calculation results showed that the priority order of analysed sensing tools was determined as follows:

$\mathrm{a}_{2}\left(0.565, \mathrm{SfM}\right.$ with action camera) $>\mathrm{a}_{1}(0.407, \mathrm{SfM}$ with Nikon D3400 macro-lens) $>$ as $(0.377$, TLS BLK360) > a4 $(0.278$, handheld structured-light scanning Artec Eva) $>$ as $(0.123$, handheld structured-light scanning Artec Spider).

From the all aspects, it was found that the most beneficial is alternative $\mathrm{a}_{2}$ - Photogrammetry with an action camera (Video). The second ranked alternative is high-resolution close-range photogrammetry with a consumer camera and macro-lens $\left(\mathrm{a}_{1}\right)$. Accordingly, from a technical point of view we can state that the both photogrammetry alternatives are evaluated positively, and can be successfully used in this projects and similar projects for surface imaging of gravestones. Using this technology is the optimal ratio of time spent on work, time and quality of the result, and the price of equipment is the lowest of those considered. Structured Light Scanners - Spider (as) and Eva (a4) are behind the best alternative respectively the third and fourth ranked. Certainly, the usage of the Artec spider requires great patience and time and a calm hand over a longer period.

The last ranked is a5 alternative BLK360 Leica Geosystems laser scanner, which is designed for terrain and landscape mapping. It is also often used for 3D scanning of large architectural objects. In this study, the accuracy and resolution delivered BLK360 is not enough, as well as high processing time, and highest price compared to other alternatives, with respect to high-resolution recording of the surface. Of course it is a great tool to put the 
gravestones into the topographical context and will provide a geographical mapping of the cemetery.

The suggested research methodology can be employed in other case studies for ranking modern technologies and tools to record, model and preserve heritage objects.

In this paper, we have described our approach for a technical solution for fast documentation by $3 \mathrm{D}$ surface recording including assessment of this feasibility study relating to criteria for speed and scalability. This is important to be able to record hundreds and potentially thousands of stones in Laudenbach cemetery as well as the many other Jewish cemeteries throughout the region and indeed, the whole of Germany. This research provides the basis for further heritage digitisation research combined with a statistical-engineering approach.

The aim is to prepare future work, and enable the recording in sufficient resolution towards the transcription of the text, potentially automating the process using optical character recognition and machine learning technologies. Another option would be citizen science transcriptions. The usability for content specialists - such as Judaists - must still be explored and is a future project.

\section{ACKNOWLEDGEMENTS}

Funding for recording campaigns was delivered by the University of Bamberg 'Centre for Heritage Conservation Studies and Technologies' (Kompetenzzentrum Denkmalwissenschaften und Denkmaltechnologien). Great thanks go to Georg Schirmer for access to Laudenbach Jewish cemetery and coordination and sustenance during the recording days. Great thanks go to Prof. Dr. Susanne Talabardon, Professorship of Jewish Studies at the University of Bamberg, an her assistant Dr. Rebekka Denz, who were instrumental to teach us about the importance of Jewish graveyards, and to put the topic into the greater context of ongoing research. We are looking forward to further collaboration and projects together.

\section{REFERENCES}

Alemannia Judaica, 2013. Arbeitsgemeinschaft für die Erforschung der Geschichte der Juden im süddeutschen und angrenzenden Raum. Der jüdische Friedhof in Laudenbach am Main (Stadt Karlstadt, Landkreis Main-Spessart). URL: http://www.alemannia-judaica.de/laudenbach_msp_ friedhof.htm (4 February 2020).

Antuchevičienė J., Stasiulionis A., 2012. Statybos verslo projektavimas ir investicijos, Technika. ISSN 9786094572456 , $190 \mathrm{p}$.

Arera-Rütenik, T., Cramer, J., Gaisberg, E. von, KuznickiFischer, S., Horn, T., Tuma, A, , Arnold, I., 2011. Der Jüdische Friedhof Weißensee. Inventarisation eines Bau-, Kultur- und Kunstdenkmalensembles, in: ICOMOS Deutschland (Hg.): Jüdische Friedhöfe und Bestattungskultur in Europa. Internationale Fachtagung, Berlin-Weißensee, 3. - 6. April 2011, ICOMOS - Hefte des Deutschen Nationalkomitees 53, 2011, 3445 .

Artec 3D, 2020. Specification of 3D Scanners. https://www.artec3d.com (5 April 2020).
Coules, H.E., Orrock, P.J., Seow, C.E., 2019. Reflectance Transformation Imaging as a tool for engineering failure analysis. Engineering Failure Analysis, 105: 1006 - 1017.

Demir, N., Yogeswaran, N., 2018. Semi-automated cemetery mapping using smartphones. Int. Arch. Photogramm. Remote Sens. Spatial Inf. Sci., XLII-5, 59-62, doi.org/10.5194/isprsarchives-XLII-5-59-2018.

Díaz-Guardamino, M., Wheatley, D. W., 2013. Rock Art and Digital Technologies: The application of reflectance transformation imaging (RTI) and 3D laser scanning to the study of late bronze age Iberian stelae. Journal of Andalusian prehistory, 3(4): $187-203$.

Earl, G., Martinez, K., Malzbender, T., 2010. Archaeological applications of polynomial texture mapping: analysis, conservation and representation. Journal of Archaeological Science, 37: 2040 - 50.

Eigen, D., Puhrsch, C., Fergus. R., 2014. Depth map prediction from a single image using a multi-scale deep network. Proceedings of the 27th International Conference on Neural Information Processing Systems, 2: 2366-2374.

Gabov, A., Bevan, G., 2011. Recording the Weathering of Outdoor Stone Monuments Using Reflectance Transformation Imaging (RTI): The Case of the Guild of All Arts. Scarborough, Ontario. Journal of the Canadian Association for Conservation, 36: $3-14$.

Ginevičius, R., Podvezko, V., 2008. Daugiakriterinio vertinimo būdų suderinamumas, Verslas: teorija ir praktika, 9(1): 73-80.

Godard, C., Mac Aodha, O., Brostow, G.J., 2017. Unsupervised Monocular Depth Estimation with Left-Right Consistency. IEEE Conference on Computer Vision and Pattern Recognition (CVPR): $6602-6611$

GoPro, 2020. Specifications of GoPro camera. https://gopro.com (5 April 2020).

Heitger, R.A., 1991. Thermal infrared imaging for the Charity Hospital Cemetery archaeological survey: implications for further geological applications. Masters thesis, University of New Orleans.

Hess, M., MacDonald, L.W., Valach, J., 2018. Application of multi-modal 2D and 3D imaging and analytical techniques to document and examine coins on the example of two Roman silver denarii. Heritage Science 6, 5. doi.org/10.1186/s40494-0180169-2.

Hwang, C. L., Yoon, K., 1981. Multiple attribute decision making - methods and application. Springer-Verlag, Berlin.

IAJGS, 2020. Instructions \& Information | International Jewish Cemetery Project [WWW Document]. IAJGS Cemetery Project. URL https://iajgscemetery.org/instructions/ (5 April 2020).

Jones, G., 2008. Geophysical mapping of historic cemeteries. Technical Briefs in historical archaeology, 3: 25 - 38.

Kersten, T. P., Lindstaedt, M., Starosta, D., 2018. Comparative geometrical accuracy investigations of hand-held 3D scanning systems - an update Int. Arch. Photogramm. Remote Sens. Spatial Inf. Sci., XLII-2, 487-494. 
Kersten, T. P., Lindstaedt, M., 2012. Potential of Automatic 3D Object Reconstruction from Multiple Images for Applications in Architecture, Cultural Heritage and Archaeology. International Journal of Heritage in the Digital Era, 1(3): 400 - 418.

Klemm, S., 2020. Jüdischer Friedhof Schopfloch: Bet-Olam. URL: $\quad$ https://www.juedischer-friedhof-schopfloch.de/ tombstoneList (4 February 2020).

Leica Geosystems 2020. Specifications of BLK 360 laserscanner. Avialable at: https://leica-geosystems.com/ products/laserscanners/scanners/blk360 (4 February 2020).

Leonavičiūtè, G., Dejjus, T., Antuchevičienè, J., 2016. Analysis and prevention of construction site accidents. Građevinar, 68(05), 399-410.

Liu, S., Lin, Y., 2010. Grey Systems: Theory and Applications, Springer-Verlag, Berlin, Heidelberg.

Luhmann, T., Chizhova, M., Gorkovchuk, D., Hastedt, H., Chachava, N., Lekveishvili, N., 2019a. Combination of terrestrial Laserscanning, UAV and close-range photogrammetry for 3D reconstruction of complex churches in Georgia, Int. Arch. Photogramm. Remote Sens. Spatial Inf. Sci., XLII-2/W11, 753761.

Luhmann, T., Robson, S., Kyle, S., Boehm, J., 2019b. Closerange photogrammetry and $3 \mathrm{D}$ imaging. $3^{\text {rd }}$ ed., Berlin: Walter de Gruyter, 822 p.

Marr, D., Poggio, T., 1976. Cooperative computation of stereo disparity. Science, 194: $282-287$.

Mathys, A., Jadinon, R., Hallot, P., 2019. Exploiting 3D multispectral texture for a better feature identification for cultural heritage, ISPRS Ann. of Photogramm. and Remote Sens. Spatial Inf. Sci., IV-2/W6, 91-97.

Miles, J., Pitts, M., Pagi H., Earl, G., 2014. New applications of photogrammetry and reflectance transformation imaging to an Easter Island statue. Antiquity, 88(340): 596 - 605.

Müller, K., 2011. Die Grabsteine vom jüdischen Friedhof in Würzburg aus der Zeit vor dem Schwarzen Tod:(1147-1346). Ges. für Fränkische Geschichte.

Steinheim Institut, 2020. epidat - Research Platform for Jewish Epigraphy, URL: http://www.steinheim-institut.de/cgibin/epidat?lang=en (4 February 2020).

Mytum, H., Peterson, J. R., 2018. The Application of Reflectance Transformation Imaging (RTI) in Historical Archaeology. Hist. Arch., 52: $489-503$.

Pavlovskis, M., Antucheviciene, J., Migilinskas, D., 2016. Application of MCDM and BIM for evaluation of asset redevelopment solutions. Studies in Informatics and Control, 25(3), 293-302.

Piquette, E.K., 2017. Illuminating the Herculaneum Papyri: Testing new imaging techniques on unrolled carbonised manuscript fragments. DCO, 3 (2): $80-102$.

Robinson, T., 2018. Comparative Headstone Analysis and Photogrammetry of Cemeteries in Orange County, Florida.
University of Central Florida Libraries. Honors Undergraduate Theses. 301.

Rütenik, T., Horn, T., von Gaisberg, E., Arnold, I., 2013. Landesdenkmalamt Berlin: 15.628 Berliner: Der jüdische Friedhof Weissensee: Dokumentation der flächendeckenden Erfassung der Grabstätten. Petersberg: Michael Imhof Verlag.

Stojčić, M., Zavadskas, E.K., Pamučar, D.,Stević, Ž., Mardani, A., 2019. Application of MCDM Methods in Sustainability Engineering: A Literature Review 2008-2018. Symmetry, 11, 350 .

Turskis, Z., Daniūnas, A., Zavadskas, E. K., \& Medzvieckas, J., 2016. Multicriteria evaluation of building foundation alternatives. Computer Aided Civil and Infrastructure Engineering, 31(9), 717-729.

Stylianidis, E., Remondino, F., 2016. 3D Recording, Documentation and Management of Cultural Heritage. Dunbeath Mill: Whittles Publishing.

Vincent, M.L., López-Menchero Bendicho, V.M., Ioannides, M., Levy, Th.E., 2017. Heritage and Archaeology in the Digital Age. Acquisition, Curation, and Dissemination of Spatial Cultural Heritage Data. Berlin: Springer, 198.

Wilm, J., 2016. Real Time Structured Light and Applications. Kgs. Lyngby: Technical University of Denmark. DTU Compute PHD-2015, No. 400.

Zavadskas, E. K., Turskis, Z., Antucheviciene, J., 2015. Selecting a contractor by using a novel method for multiple attribute analysis: Weighted Aggregated Sum Product Assessment with grey values (WASPAS-G), Studies in Informatics and Control, 24, 141-150.

Zavadskas, E. K., Turskis, Z., Antucheviciene, J., Zakarevicius, A., 2012. Optimization of Weighted Aggregated Sum Product Assessment. Electronics and Electrical Engineering = Elektronika ir Elektrotechnika,. 122,. 3-6.

Zavadskas, E.K., Govindan, K., Antuchevičienė, J., Turskis, Z., 2016. Hybrid multiple criteria decision-making methods: A review of applications for sustainability issues. Econ. Res. Ekonomska Istraživanja 29, 857-887.

Zavadskas, E. K., Antucheviciene, J., Vilutiene, T., Adeli, H., 2018. Sustainable decision-making in civil engineering, construction and building technology. Sustainability, 10(1), 14. 